\title{
Thinking of Corporation Financial Management Innovation in the Era of Big Data
}

\author{
Jun-Ya Cheng ${ }^{1, a,{ }^{*}, \text { Pei-Wu Dong }}{ }^{2, b}$ \\ ${ }^{1}$ Beijing Institute of Technology, HaiDian District, Beijing, China \\ ${ }^{2}$ Main Building, Beijing Institute of Technology, HaiDian District, Beijing, China \\ achjunya@163.com, bongpeiwu@bit.edu.cn \\ ${ }^{*}$ Corresponding author
}

Keywords: Big data, Corporation financial management, Innovation.

\begin{abstract}
The explosive increase of data amount and data complexity leads human society to the era of big data. In order to survive in the changed environment, corporation management needs to innovate immediately, especially the financial management department, where most data aggregates and gets analyzed. Given scarce researches on corporation financial management innovation in the era of big data, this paper summaries four opportunities and four challenges faced by corporation financial management nowadays, gives clear instructions of the no-border management and data resources expansion to prepare for the innovation, and explains how to effectively use big data to help corporation financial management innovate following the sequence of big data analysis and big data application. Though there will still be plenty of problems in this field as listed to be further discussed, this paper hopes to make an initial contribution and inspire more researches for future progress.
\end{abstract}

\section{Introduction}

According to the report from International Data Corporation: Until 2011, the amount of data had been created and replicated worldwide passed 1.8ZB, and is even expected to jump to 35ZB in 2020. Accompanied by the sharp growth of data complexity, the era of big data has arrived, marking human society moves from the information and knowledge community to the intelligence community [1].

Characterized by volume, variety, velocity and value, big data refers to valuable information assets extracted from the huge amount of various data collection at high speed through technical selecting and processing [2]. As another disruptive technology revolution in IT industry following cloud computing and networking, big data has permeated almost all industries and fields, becoming a new production element and valuable social asset [3]. As a result, decision making of corporation management increasingly rely on data analysis rather than experience or intuition [4]. Besides, the applications of big data for business analysis have already generated tremendous social value in medical services, retail, finance, manufacturing, logistics, and telecommunications industries [5, 6].

In the era of big data, both inside and outside boundaries of corporation are expanding, so its internal departments must make adjustments while its external business analysis is been upgrading. Especially the financial management, facing the wider sources and broader types of information, it needs to analyze not only the traditional structured financial data, but also the mass of unstructured data [7]. Existed researches have already pointed out the significance of management innovation [8]. Taking the economic growth in China as an example, the contribution of management innovation accounted for about $70 \%$ of the total contribution of generalized technological advances [9]. However, the implementation of corporation financial management innovation still lacks of specific and practical theory support. Therefore, this paper aims at dialectically summarizing previous studies and clearly suggesting innovation measures for corporation financial management in the era of big data.

\section{Organization of the Text}

Section 1: dialectically summarize the opportunities and challenges faced by corporation financial management in the era of big data. 
Section 2: clarify preparations that corporation financial management should make for innovation

Section 3: suggest in-detail measures to promote corporation financial management innovation

Section 4: propose relative problems for further discussions and researches

\section{Opportunities and Challenges Faced by Corporation Financial Management}

The era of big data brings corporation financial management not only opportunities, but also challenges. Hence, thus paper dialectically summarizes those effects.

\section{Opportunities}

The opportunities faced by corporation financial management in the era of big data can be summarized into four aspects.

Firstly, corporations can process and discovery certain finance data with commercial value in a timely manner, thus accurately make the optimal decisions and seize the development opportunities.

Secondly, corporations can in-depth understand customers' consumption levels, spending habits and hobbies through analyzing complex sale data, resulting in finding potential customers and improving own products and services.

Thirdly, corporations can classify and mine effective operation data, hence enhance its market competitiveness and improve its capacity for sustainable development.

Fourthly, corporations can find out the harmful factors by screening and analyzing synthesized data, therefore avoid or treat financial risks in a scientific and rational way.

\section{Challenges}

The challenges faced by corporation financial management in the era of big data can also be summarized into four aspects.

Firstly, the use of big data requires corporations to break the data segment among business lines and departments, which means to highly integrate financial information and business information.

Secondly, there is a certain degree of technical difficulty for big data transfer, storage and analysis, while corporation data management is lagging behind, thus not able to timely analyze data and offer support to decision making.

Thirdly, although it becomes much easier to obtain customers' consumer level, hobbies and habits in complex data environment, such information is likely to constitute a violation to their privacy.

Fourthly, the hardware and software for the application of big data are not yet mature, and professional personnel is not enough $[10,11]$.

\section{Preparations for Corporation Financial Management Innovation}

Before applying big data to financial management innovation, corporation should make some necessary preparations mainly including first, to further enhance the management information level, second, to accelerate the upgrade of financial software modules and third, to strengthen the quality of management team. Since there are plenty of sub-preparations under these three factors, if comprehensively introduce them, it will be too broad to master the essences. To avoid generalities, the paper picks two of the most important points to elaborate, namely the no-border management and data resource expansion.

\section{No-border Management}

In order to adapt to changes brought by the era of big data, financial management has to continually expand its boundaries and converge with externals. Currently, this trend becomes more and more obvious, reflecting in not only the fusion of finance and accounting, financial accounting and management accounting, but also the integration in new areas, such as financial management and business operations, industrial capital and financial capital and so on. Therefore, breaking through the limitations of traditional financial management, extending and infiltrating to various departments including production, sales and human resources, meanwhile collecting, processing and analyzing data related to important business become the primary task of corporation financial management. The idea of no-border financial management thus comes into being [7]. 
This idea is developed from the conception of borderless management created by Jack Welch, previous CEO of GM. This theory does not mean that corporations really have no borders, but stresses the organic and permeability of various organization boundaries, and seeks to make quick and creative reactions to the changes of external business environment. When it comes to financial management, it encourages financial department to actively implement the no-border management on the basis of the corporation strategy. Specially, financial department needs to break the existing framework and model, communicate and conduct financial concepts in all links of the value chain to form the integration with other departments. Only by this way, can the departmental and professional barriers of information communication be broke down, can information delivery, diffusion and penetration throughout the organization be improved, and can the optimize resource allocation and sustainable growth of the corporation overall value be achieved.

\section{Data Resource Expansion}

Data is the basis for every kind of work, and also an unparalleled advantage of financial department. Entering the era of big data, the original data cannot meet the requirement of daily management any more, therefore corporation needs to not only root out financial data resources from two angles of financial accounting and management accounting, but also dig its business data resources to achieve the integration of financial management and business operations. Equipped with effective data collection and storage, the data support can thus be well provided to fully play the function of financial management [12].

Financial data. On the one hand of external reporting responsibility, based on the complete system of norms and modern information technology, current financial accounting has already accumulated a lot of fundamental financial data through the recognition, measurement and recording procedures. Hence, it can provide adequate financial information support to reflect the fulfillment status of fiduciary duty and make business decision. On the other hand of internal management responsibility, management accounting is playing an increasingly important role. On the basis of financial accounting data, financial workers need to arrange and process data in accordance with the demand of the internal management, and fully dig the intrinsic value of financial data resources to offer reasonable suggestions to improve corporation governance, indirectly promote the efficiency and help push business growth.

Business data. Economic and business activities of corporations are the basis of financial management. Business data such as business contract data, raw material prices data, and industry trend data and so on has become an indispensable factor for financial forecasting and decision-making. The era of big data requires financial workers extend management tentacles to business operation, industrial chain and even external environment, in order to timely and adequately access to business data related to internal management decisions.

Data collection and storage. Extensive collection of authentic and reliable data is the basis and key to play the value of data resources. From a macro perspective, relevant government departments need to strengthen the top-level design and specification guidance. At the micro level, corporations should grasp of the needs of management decisions and establish data collection framework through reverse tracing based on the actual situation. Building a good database is also an important guarantee to play the value of data resources, which will directly affect the efficiency and quality of data analysis. On the side of hardware, current level of storage server technology is enough to support corporation-class needs. On the side of software, corporations should prospectively plan the database structure within a certain range of integrated data, reflecting refinement, standardization and scalability in data elements classification, organizational structure level and data time/period dimensions etc., to provide conditions to efficiently carry data retrieval, integration, mining and analysis in high quality.

\section{Use of Big Data to Promote Corporation Financial Management Innovation}

On the basis of preparation, corporations should started to promote the innovation of financial management through the use of big data. This process mainly relates to two steps, namely big data analytics and big data application.

\section{Big Data Analytics}

As the "new oil" for corporations in the future, the value of data resources will be forever "buried" if they failed to receive timely and effective "exploitation", therefore financial workers in the new era should initiatively apply the awareness of data analysis throughout the process of daily financial 
management, awaken historical data and let the data "speak" to offer information support for decision-making. Specific approach can be divided into three steps, namely data integration, data processing and data mining [13].

Data integration. The determinant of the future financial management development direction is how to integrate disperse and massive data sources in a more rapid and more effective way. To achieve this goal, the action strategy should be firstly planned, which means to set up a leading group or specialized agency, and then carry out data management within the upper-led strategic framework. Next, the data standards needs to be made to solve the problem of non-uniform among various departments. Finally, data integration can be launched based on software development and personnel training. In general, initial data integration cannot completely replace manual operation, using both modes in parallel is recommended.

Data processing. Strategic significance of big data is not mastering bulky data information, but professionally dealing with these meaningful data. The only way to perform dynamic analysis of big data without the use of sampling tools is to find the correlations between big data, so that the data with relevant characteristics can be classified together and analyzed, resulting in knowing changes of the data just by observing the correlation coefficients. It is especially beneficial for time saving and complex analysis conclusion avoidance.

Data mining. Corporations need to explore single indicator or composite indicators after big data processing to explain the truth. Namely, "find the data behind the data, find the reasons behind the phenomenon".

\section{Big Data Application}

In the era of big data, competition among corporations does not focus on labor productivity, but on knowledge productivity. Modern corporation financial management should make full use of big data analytics to mine important information, to support management decisions, and to indirectly promote corporation performance. This article divides the application of big data for corporation financial management innovation into five aspects to explain in detail [9].

Firstly, enable corporation to timely discover and understand its competitors. In the process of screening and analyzing big data, corporation should pay attention to digging potential competitors and investigating key information of them such as their background, price and benefits. Corporations must make reasonable countermeasures against competitors to grab more market share and win the final victory.

Secondly, timely seize business opportunities. According to the current situation that government continues to support the development of digitization coupled with the popularity of mobile devices for data transmission, the business opportunity of finding new consumer groups is brought to corporations. Corporations must seize it by analyzing available data information to provide the basis for discovering and selecting the products market, consumer level and consumer demand.

Thirdly, to make the best decisions. Corporations must make the best use of the data for effective data processing and in-depth analysis to offer the basis for strengthening the capacity and speed of decision-making, avoiding the financial risks, improving internal control and enhancing market competitiveness

Fourthly, help carry out product marketing and promotion. Corporations must firstly establish a strong timeliness dynamic data systems, next determine the client objectives to overcome through processing and in-depth analyzing dynamic sales data, finally timely and accurately grasp the demand of those customer and correspondingly improve the products and services.

Fifthly, reduce operating costs. Corporations can take advantage of various financial information from big data, thus enable leaders to know the working states of every departments to better organize the internal resources, eventually resulting in scientific and efficient business operations and cost savings.

\section{Problems for Further Discussion}

Promoting corporation financial management innovation through the application of big data belongs to subject frontier, and many issues are still under discussion, so there will inevitably be a lot of problems in the future. First, who will do it? Given the hardware and software development of big data and relevant 
personnel reservation will benefit the whole society, it seems that the government is more suitable for leading this career. However, if the government take on everything, then different companies in different industries need to make adjustments to its own characteristics and development, probably resulting in a waste of manpower and financial resources. Second, which accounting standards should be used? Since the current accounting standards of mainland China differs from the international accounting standards, should corporations use the international one to help go abroad or just follow the traditional one is a question needed to be carefully considered. Third, how to measure the pros and cons of innovation? Construction and development of big data will inevitably lead to money-cost and time-consuming in the initial stage. If using proceeds to measure the innovation project, the judgment may lose fairness, thus forming negative comments, so a feasible and scientific measure method requires continual exploration [14].

\section{Summary}

In the era of big data, corporations are facing wider and wider data range as well as more and more complete chain of causation. As the department that masters most data and has the highest data demand, financial management is meeting the new requirement of restructuring and the chance of innovation put forward by big data. This paper dialectically summarizes the opportunities and challenges faced by corporation financial management innovation in era of big data, based on which gives clear guidance of preparations for innovation, and analyzes how to use big data to promote innovation in detail. In the end, the paper discusses some issues which may appear in the future, and may become the direction of future researches.

Financial workers in this new era need to train the data thinking, and strengthen the exploration and innovation in data collection, storage, analysis and application. Finally, big data needs to be presented in a visualized way and traditional financial management needs to be transformed into strategic, converged, precise and informational financial management. Only by this way, can financial management become more proactive and wise to provide more support to business decisions.

\section{Acknowledgement}

Thanks for previous literatures in this field listed in references, from which the writers got inspirations and based on which this paper is finally finished.

\section{References}

[1] J. Gantz, D. Reinsel, Digital Universe Study: Extracting Value from Chaos, M. IDC Go-to-Market Services. (2011).

[2] C. Wang, Government Management Innovation in the Era of Big Data, J. Journal of CPC Fujian Provincial Committee Party School. 10 (2014) 7.

[3] S. Sagiroglu, D. Sinanc, Big data: A review, J. Collaboration Technologies and Systems (CTS) 2013 International Conference. (2013) 42-47.

[4] Q. Wang, X. Zhu, Thinking of Corporation Human Resource Management Innovation in the Era of Big Data, J. Journal of Shenyang University of Technology (Vision of Social Sciences). (2015).

[5] Z. Feng, X. Guo, D. Zeng, Y. Chen, G. Chen, Several Business Management Research Topics at the Forefront of Big Data Background, J. Journal of Management Science. 16 (2013) 1-9.

[6] B. Kayyali, D. Knott, S. Van Kuiken, The Big-data Revolution in US Health Care: Accelerating Value and Innovation, Mc Kinsey \& Company. (2013).

[7] Y. He, Y. Peng, D. Zhang, Borderless Financial Management Innovation in the Era of Big Data, J. Finance and Accounting. 12 (2014). 
[8] G. Hamel, The Why, What, and How of Management Innovation, J. Harvard Business Review. 84 (2006) 1-11.

[9] Z. Li, C. Lu, Quantitative Analysis about Contribution of Management Innovation to the Economic Growth, J. Journal of Tsinghua University (Visin of Philosophy and Social Sciences). 17 (2002), 25-31.

[10] X. Liu, Initial Discussion about the Corporation Financial Management in the Era of Big Data, J. Financial Times. 20 (2014) 99.

[11] X. Zhang, X. Fan, Shallow Thinking about Corporation Financial Management in the Era of Big Data, J. Market Modernization. 2 (2014) 166.

[12] Z. Wang, The Era of Big Data and Enterprise Financial Management Transformation, J. Finance and Accounting. 6 (2014) 39.

[13] N. Cui, Construction of Big Data Applications System for Financial Management in Airline Enterprises, J. China's Civil Aviation. 11(2013) 64-65.

[14] R. Adams, J. Bessant, R. Phelps, Innovation Management Measurement: A Review, J. International Journal of Management Reviews, 8 (2006) 21-47. 